\title{
A Pártia e os Partos nos Anais de Tácito
}

\author{
Matheus Treuk Medeiros de Araujo
}

ReSUMO: Os Anais de Tácito constituem uma das principais fontes narrativas para a história do Império Parto. Considerando a profunda inimizade romana em relação à Pártia, contudo, nem sempre é fácil dizer como se deveria interpretar essa obra. Este artigo resume múltiplos aspectos da descrição taciteana da Pártia e dos partos, abordando questões de credibilidade e representação dos outros. Através de uma análise contextual de alusões e ressonâncias narrativas, esforçase por demonstrar que a avaliação de Tácito dos arsácidas é bastante complexa. Como outros autores romanos, Tácito expressa, efetivamente, desprezo genérico em relação aos inimigos iranianos, mas também associa, implicitamente, Roma à Pártia, atenuando, por conseguinte, as fronteiras entre ambos. Em segundo lugar, examina-se brevemente a persistência da ideia de divisio orbis nos Anais. Por fim, o autor aborda questões relativas à relevância de Tácito para o estudo do Império Parto. Conclui-se que as descrições de Tácito são, de fato, de grande valor para a História Antiga do Irã, mas apenas se cuidadosamente apreciadas.

PALAVRAS-ChaVE: Tácito; Arsácidas; Pártia; Historiografia.

ABSTRACT: Tacitus' Annals are one of our main narrative sources for the history of the Parthian Empire. In the light of Roman profound enmity towards Parthia, however, it is not always easy to assert how one should interpret this work. This paper summarizes multiple aspects of Tacitus' description of Parthia and Parthians, addressing questions of credibility and representation of others. Through contextual analysis of narrative allusions and resonances, one strives to show that Tacitus' evaluation of the Arsacids is rather complex. As other Roman authors, Tacitus does show general disregard towards his Iranian foes, but also implicitly associates Parthia to Rome, therefore attenuating the frontiers between both. Secondly, the author examines the persistence of the idea of divisio orbis in the Annals. Finally, one addresses questions concerning Tacitus' relevance to the study of the Parthian Empire. The author concludes that Tacitus' descriptions are indeed of great value to the history of Ancient Iran, but only if carefully appreciated.

KEYWORDS: Tacitus; Arsacids; Parthia; Historiography.

${ }^{1}$ Doutorando em História Social pela Universidade de São Paulo. Pesquisador do Laboratório do Antigo Oriente Próximo. Bolsista regular da Fundação de Amparo à Pesquisa do Estado de São Paulo (FAPESP - Processo n. ${ }^{\circ}$ 2016/14318-o) com estágio doutoral na École Française de Rome sob financiamento da Coordenação de Aperfeiçoamento de Pessoal de Nível Superior (CAPES Processo n. ${ }^{\circ}$ 88881.135183/2016-01). E-mail: mathtreuk@gmail.com. 
O visitante que transita pelos museus e monumentos históricos de Roma logo se dá conta da importante presença da Pártia e dos partos na retórica imperial. Do arco de Severo, no Fórum Romano, à estátua de Prima Porta, ${ }^{2}$ no Museu do Vaticano, constata-se que os discursos de sujeição dos arsácidas tiveram um destaque especial na propaganda política dos imperadores de Roma. A evidência numismática, com suas múltiplas referências às vitórias contra o vizinho oriental, não é menos expressiva (Rose, 2005). Nada mais natural, portanto, do que a crescente produção historiográfica sobre a Pártia e os partos na documentação latina.

Sabemos pelas fontes literárias do período romano que os partos foram competentes adversários da República e do Império. A poesia da era de Augusto revela alguma consciência das questões estratégicas envolvidas no embate com os partos e, como é nítido, reverbera a propaganda imperial (Wisseman, 1982, p. 129-132). 3 “Quem temeria o parto (...) enquanto César está incólume?” (Horácio Carm. 4.5; tradução de Nogueira, 2006, p. 61). A historiografia latina manifesta preocupação equivalente com a posição do Império Romano perante os arsácidas. E, dentro dessa última tradição literária, destaca-se Tácito como um autor notavelmente interessado pela fronteira oriental.

Para os romanos, a Pártia passou cedo ao tradicional imaginário do Oriente afeminado, lascivo e submisso (Brosius, 2006, p. 136-138). Uma marca característica da dinastia arsácida, como vemos mesmo em Tácito (Ann. 11.8.2; 10.3; 10.4), é a insuportável crueldade de seus monarcas, um clichê que contribuía à veiculação da ideia de "despotismo oriental". ${ }^{4}$ Fala-se, ademais, das disputas fratricidas da corte, da poliginia bárbara e da influência das mulheres na política (Lerouge, 2007, p. 260-265). Sobretudo após Augusto, os partos são representados na estatuária de edificações públicas, às vezes de joelhos, geralmente servindo de apoio, em sinal de submissão. Esculpidas em mármore colorido ori-

\footnotetext{
${ }^{2}$ Há interpretações divergentes sobre a imagem na armadura da estátua de Prima Porta. Simpson (2005) sugere que a figura central da couraça não deva ser identificada como um parto.

3 A partir de 20 a.C., quando Augusto finalmente recupera os estandartes perdidos na Batalha de Carras, os poetas latinos passam a representar a Pártia como um reino vassalo. Seu tratamento da Pártia se conforma aos interesses de cada momento: antes do acordo, os partos são inimigos hostis e, depois, vassalos submissos (Wisseman, 1982, p. 130).

4 Os romanos conheciam a doutrina grega, apesar de empregarem uma terminologia própria (Koebner, 1951, p. 278).
} 
ental e trajando os tradicionais barretes frígios, as imagens reforçavam a alteridade dos partos para o público romano (Schneider, 1986, p. 19-20; 39-45; 161162; Brosius, 2006, p. 137).

Apesar de unidas por clichês sobre a ferocidade, incivilidade e despotismo dos partos, as fontes do período romano costumam ser separadas em no mínimo três períodos distintos, com algumas nuances. A classificação visa explicar diferentes atitudes dos autores latinos perante os partos conforme o interesse estratégico da vez. O esquema é, grosso modo, o seguinte: na República, e pelo menos até o fracasso de Carras (Carrhae), em 53 a.C., diz-se que a Pártia não assume um caráter específico na literatura latina (Lerouge, 2007, p. 81). Mais tarde, sob Augusto, uma política diplomática particular enfatiza a grandeza militar da Pártia, sua degradação moral e a necessidade de uma postura defensiva que evitasse o arriscado combate e a "contaminação" por um Oriente degenerado (Sonnabend, 1986, p. 197-229). Trajano, seguido, em particular, por Marco Aurélio, Severo e Caracala - e, se formos mais longe, já no período sassânida, por Juliano, o Apóstata -, faz do empreendimento conquistador um tema central de sua propaganda e política em relação à Pártia, à maneira de um Alexandre, o Grande, que havia submetido a Pérsia Aquemênida (Lerouge, 2007, p. 149-165).

Não é novidade que Tácito contribuiu definitivamente para nosso conhecimento dos partos. No entanto, se, de um lado, os Anais recontam a história da dinastia Julio-Claudiana, de outro, eles foram produzidos sob o domínio dos Nerva-Antoninos. Nessa interface de dois mundos, duas posturas alegadamente distintas em relação à Pártia, se encontram as descrições de política externa do historiador. Tentamos entender o lugar da Pártia em sua narrativa nas linhas seguintes.

Era uma vez no Leste...

A reconstrução da história política da Pártia arsácida esbarra em inúmeras dificuldades ligadas à natureza das fontes disponíveis. É verdade que esse problema não é exclusividade do período arsácida, e os especialistas da Pérsia aquemênida não raro confessam enfrentar obstáculos similares. A carência de fontes locais, contudo, é de longe mais pronunciada neste período da história do Irã pré- 
islâmico, resultando na dependência bastante questionável de fontes gregas e latinas para sua reconstrução. Como decorrência, arrisca-se, de forma geral, proceder a raciocínios frágeis e tautológicos em grande parte das análises históricas das próprias narrativas romanas sobre os partos.

Duas respeitadas histórias políticas do Império Arsácida foram escritas por Debevoise (1938) e Bivar (1983)5 e permitem aferir o estado lacunar do nosso conhecimento. As melhores obras de síntese (Wiesehöfer, 2001; 2003; Brosius, 2006), por sua própria natureza, não esclarecem opções pelas teorias que se multiplicam sobre a origem e cronologia dinástica dos partos, mas são suficientes para se ter uma visão geral da sua trajetória. Para os propósitos desse estudo, uma brevíssima introdução histórica é inevitável.

A satrapia da Pártia, na região nordeste do atual Irã, existia formalmente desde pelo menos a inscrição de Dario I em Behistun, no final do século VI a.C. (DB, §6: " $\theta$ ātiy Dārayavauš xšāyaقiya: imā dahyāva tayā manā patiyāiša... ParӨava...”). ${ }^{6}$ No período selêucida, após a rebelião de um sátrapa local, Andrágoras, a região foi tomada por um povo de língua iraniana, os "parnos" (parni). Por volta de 238 a.C., Arsaces, o líder dos parnos, derrotou Andrágoras e, mais tarde, repeliu uma expedição punitiva de Seleuco II. Com o tempo, esse povo passou a ser denominado "parto", enquanto a dinastia reinante obteve seu nome do fundador, Arsaces I (Bivar, 1983, p. 31).

A verdadeira fase de expansão parta se inicia, segundo a opinião unânime dos especialistas, com o reinado de Mitrídates I (171-139/138 a.C.), quando os arsácidas conquistam a Média, a Mesopotâmia e parcelas do Reino Greco-Báctrio (Wiesehöfer, 2003, p. 91; Brosius, 2006, p. 86-90; Bivar, 1983, p. 32-35). Os sucessores de Mitrídates, Fraates II (c. 139/8-128 a.C.) e Artabano II (c. 128-124/3 a.C.), se veem ameaçados por dificuldades na fronteira oriental e na Mesopotâmia, mas Mitrídates II (124/3-87 a.C.) assegura e consolida o domínio dos arsácidas nos dois fronts (Bivar, 1983, p. 36-41).

Pouco antes das Guerras Mitridáticas, contra Pontus, arsácidas e romanos se encontram pela primeira vez (Lerouge, 2007, p. 42). O Eufrates é, a seguir, reconhecido como fronteira entre a Pártia e Roma (Wiesehöfer, 2003, p. 92).

\footnotetext{
5 Que segue e atualiza Debevoise (Bivar, 1983, p. 23).

6 “Diz Dario, o rei: estes países são aqueles que vieram a mim... a Pártia...” (Schmitt, 1991, p. 27).
} 
Vistos até então como inimigos de menor importância, os partos se tornam perigosos adversários com o fracasso retumbante de Crasso em Carras, em 53 a.C. (Wiesehöfer, 2003, p. 92). Crasso havia sido nomeado governador da Síria e, se pudermos acreditar na biografia escrita por Plutarco (Vit. Crass. 16-18),7 arriscou uma campanha contra a Pártia por puro prestígio pessoal. É provável que uma disputa dinástica entre Orodes II e Mitrídates III tenha favorecido a decisão de Crasso, que terminou tendo a cabeça oferecida a Orodes, como se fosse Penteu, numa encenação de As Bacantes de Eurípides (Bivar, 1983, p. 49-56).

Após a derrota de Crasso, o próprio Júlio César planejou um ataque à Pártia, mas o empreendimento foi abortado em razão de sua morte precoce (Debevoise, 1938, p. 106). Uma malfadada campanha de Marco Antônio no atual Azerbaijão acrescenta-se à lista de fracassos romanos contra a Pártia (Bivar, 1983, p. 58-66).

Durante a Guerra Civil, os partos forneceram apoio à facção republicana de Cássio e seu enviado, Labieno (Brosius, 2006, p. 96). Segundo Dieter Timpe (1962, p. 118), a próxima associação entre Pártia e os derrotados republicanos explica, em grande medida, a escolha dos arsácidas como principais adversários dos imperadores romanos a partir de Augusto, e a batalha de Carras não teria tido um significado especial até então. Seja como for, é também a partir de Augusto que a história da Pártia passa ao centro de interesse de Tácito, o que exige maior detalhamento no relato a seguir.

Em 20 a.C., Augusto adota uma política de conciliação com os partos e celebra um acordo com Fraates IV, resgatando os estandartes perdidos em Carras, alguns prisioneiros romanos e o controle da Armênia. Festejado como uma grande vitória em Roma, o episódio não envolveu esforços militares, mas consagrou a fama de Augusto como um governante habilidoso. Para reforçar seu pacto com Fraates, o imperador romano também presenteou o rei com uma escrava italiana conhecida como Thea Musa, ${ }^{8}$ que logo daria à luz um filho, o futuro Fraates V (Bivar, 1983, p. 67; Debevoise, 1938, p. 143).

\footnotetext{
7 Em vit. Crass., Plutarco descreve a embaixada arsácida em termos favoráveis (18.1-2) e fornece, ainda, informações sobre o exército parto (18.7), a cidade de Selêucia (32.3-4) e a corte parta $(32.5)$.

${ }^{8}$ O nome assim é grafado em moedas; “Thermusa” em Josefo (Bivar, 1983, p. 67).
} 
Por volta de 10 a.C., Musa, mulher influente na corte e, agora, a preferida do rei, convenceu Fraates a exilar quatro filhos oriundos de outros matrimônios, abrindo caminho para a sucessão do seu filho, Fraates V. Alguns anos depois, a rainha teria envenenado o próprio Fraates IV e assegurado a sucessão do filho, com o qual reinou como consorte, em alegado incesto (Bivar, 1983, p. 68; Debevoise, 1938, p. 147). 9 Uma revolta acabou cedo com o reinado de Fraates V, e seu sucessor, Orodes III, foi brutalmente assassinado.

A crise na Pártia faz com que legados partos requeiram a Roma o retorno de Vonones, um dos filhos de Fraates IV que havia sido afastado a pedido de Musa. Odiado por seus modos estrangeiros, Vonones (c. 8-12 d.C.) é rapidamente substituído por Artabano III,10 e é nessa época que Tibério envia Germânico à Síria para retomar o controle da Armênia e pacificar a fronteira oriental (Bivar, 1983, p. 68-69; Debevoise, 1938, p. 153-154).

Em 35 d.C., após mais de uma década de tranquilidade na região (Bivar, 1983, p. 69), o imperador Tibério, ao lado de membros da nobreza parta, maquina contra Artabano e envia Fraates à Síria a fim de promover uma revolta na Pártia (Debevoise, 1938, p. 157). O jovem príncipe morre antes de completar seus intentos, mas Tibério escolhe outro pretendente ao trono para minar o reinado de Artabano, desta feita um certo Tirídates (Debevoise, 1938, p. 158). Após estabelecer o irmão do rei da Ibéria no comando da Armênia, expulsando os arsácidas, os aliados de Roma derrotam em combate Orodes, filho de Artabano, e o próprio Artabano, que se retira para o extremo leste do império. Tirídates III se torna rei da Pártia por breve período, apenas para ser repelido por Artabano (Debevoise, 1938, p. 162). Roma, representada pelo governador da Síria, Vitélio, celebra um acordo com a Pártia, cujo conteúdo nos é conhecido apenas em linhas gerais (Bivar, 1983, p. 74).

Com a morte de Artabano III, em 38 d.C., seus filhos Vardanes e Gotarzes disputam pelo trono. Roma, aproveitando-se da divisão interna na Pártia, retoma o controle da Armênia por meio de um aliado, Mitrídates. Em 45 d.C., Vardanes é assassinado e Gotarzes II assume o trono, sendo logo expulso por parte da aristocracia parta, que pede ao imperador Cláudio que envie como pretendente ao

\footnotetext{
9 Uniões incestuosas eram promovidas pelo zoroastrismo.

${ }^{10}$ Pela "nova cronologia", Artabano II, pela "velha cronologia”, Artabano III. A "nova cronologia", contestável, considera mítico o reinado de Artabano I, alterando a contagem (cf. Bivar, 1983).
} 
trono o neto de Fraates IV, Meherdates. Isso é exatamente o que o imperador faz. Sem sucesso, contudo, o derrotado Meherdates é humilhado, mas poupado, por Gotarzes II (Bivar, 1983, p. 75-78).

A morte de Gotarzes II (51 d.C.) conduz a mais uma crise entre romanos e partos. Vonones II assume o trono por apenas alguns meses e seu filho, Vologeses I, inicia uma ofensiva contra a Armênia, onde instaura como rei seu irmão Tirídates, expulsando Radamisto, filho do rei da Ibéria (Bivar, 1983, p. 79). Em Roma, Nero sucede a Cláudio (54 d.C.) e, inconformado com a situação da Armênia, envia Cneu Domício Córbulo para resolver a crise. A primeira campanha romana é um sucesso, com a tomada de Tigranocerta (59 d.C.; Debevoise, 1938, p. 184), mas os partos reagem com um cerco a esta cidade armênia. Negociações interrompem a atuação de Córbulo, que é sucedido por Cesênio Peto no comando da questão armênia (Bivar, 1983, p. 84). Com o fracasso humilhante deste último (Debevoise, 1938, p. 190), e o retorno de Córbulo, os partos decidem ceder e Tirídates aceita receber seu diadema diretamente das mãos de Nero, a quem presta homenagem em Nápoles (Bivar, 1983, p. 83-85).

O final do primeiro século cristão representa uma nova fase nas relações entre partos e romanos. Vologeses, que permanece no trono até 79 d.C., mantém relações amigáveis com Flávio Vespasiano. Domiciano, contudo, já expressa elevadas pretensões de conquistas no Oriente (Debevoise, 1938, p. 215). Após a ingerência indevida de Osróes nos assuntos armênios, Trajano prepara uma grandiosa campanha punitiva contra os Partos (114-117 d.C.; Bivar, 1983, p. 87). A tomada de Ctesifonte e a anexação de territórios a leste do rio Eufrates, façanhas notáveis, foram, contudo, parcialmente revertidas durante o reinado de Adriano (Brosius, 2006, p. 100). Ataques similares à Pártia, com a tomada das principais cidades ocidentais do império, se repetiriam durante os reinados de Severo e Caracala (Brosius, 2006, p. 100).

\section{Distopia e narrativa Taciteana}

Infere-se por uma carta de Plínio, o Jovem, que Gaius (ou Publius) Cornelius Tacitus deve ter nascido por volta de 56 d.C. (Jackson, 1992, p. 228; Syme, 
1958, p. 63). A data, entretanto, é incerta, assim como seus antecedentes familiares e o local de seu nascimento. ${ }^{11} \mathrm{O}$ próprio autor revela que teria se casado com a filha de Cneu Júlio Agrícola em 77 d.C. (Syme, 1958, p. 64) e que teria sido promovido ao longo de sua carreira pelos três imperadores Flavianos (Syme, 1958, p. 65). No reinado de Domiciano, ele certamente ocupara a posição de pretor (Syme, 1958, p. 64) e, como sua obra permite supor, testemunhou os últimos terríveis anos daquele imperador. Tácito viveu até os reinados de Nerva, Trajano e Adriano, e teria composto e publicado seus Anais nos últimos anos do segundo da lista (Syme, 1958, 465-474). De sua autoria são também as Histórias, uma narrativa política de seu tempo, e obras menores, como uma biografia do sogro, Agrícola.

Os Anais não chegaram intactos até nós, mas há farto material para episódios dos reinados de Tibério, Cláudio e Nero. Como era tradicional na historiografia latina, tratam de temas de política doméstica e externa e, mais precisamente, seguem dois Leitmotive principais. De um lado, abordando a relação entre os imperadores romanos e o senado, os Anais denunciam a gradual perda da liberdade (libertas) face aos imperadores Julio-Claudianos e a ascensão de uma postura adulatória e servil por parte dos senadores (Oakley, 2010, p. 185). De outro, a "domesticação" do ambiente público, manifesta pela (assim percebida) usurpação do poder político pelas mulheres imperiais, escravos e libertos, é especialmente relevante (Milnor, 2009). Ambos os fenômenos são apresentados como um estado de degeneração crescente se comparado ao passado ideal da República Romana, quando o senado detinha proeminência e liberdade de ação e o espaço público não se deixava contaminar pelo privado.

A literatura especializada sobre a representação dos partos em Tácito, ou nas fontes latinas em geral, está, majoritariamente, em língua alemã. A obra de Gerold Walser (1951), lidando sobretudo com a questão da fiabilidade histórica, foi seguida pela monografia de Holger Sonnabend (1986). A mais recente publicação de Norbert Ehrhardt (1998) sobre os partos em Tácito perscruta, em especial, sua importância enquanto fonte para o passado arsácida. Os trabalhos gerais envolvem uma monografia de Michael Wisseman sobre a poesia latina (1982) e a recente obra (em francês) de Charlotte Lerouge (2007).

${ }^{11}$ Para uma discussão completa sobre os antecedentes familiares de Tácito, cf. Syme, 1958, p. 611624. 
Ao examinar a imagem dos arsácidas em Tácito, portanto, um importante desafio é considerar seu contexto histórico e as contribuições trazidas por alguns desses autores sobre sua credibilidade factual. De outro lado, é preciso inserir a construção desta imagem dentro do contexto mais amplo da narrativa dos Anais, expondo ao leitor os expedientes narratológicos que servem à veiculação de uma mensagem crítica à dinastia Julio-Claudiana, conforme acima delineado. Assim, a retórica de Tácito não deve ser lida exclusivamente como um simples óbice à revelação da "verdade histórica", mas como um objeto de exame em si mesmo, sendo necessário esclarecer suas consequências para a avaliação taciteana da Pártia.

Partos, Pártia e Oriente nos Anais

A Pártia é representada de forma preponderantemente negativa nos Anais, como seria de se esperar. Uma síntese dos juízos negativos é fornecida por Ehrhardt (1998, p. 302-303): os partos, como os armênios, são pouco confiáveis, traiçoeiros e hipócritas, como quando pretendem enganar Córbulo durante as negociações de armistício (13.38). Eles são, ainda, politicamente instáveis, sanguinários e cruéis. Poderíamos pensar, ademais, na covardia e impetuosidade dos partos, sugeridas em diferentes momentos (por exemplo, 15.4). Assim, para Ehrhardt, "a avaliação de Tácito dos partos e de sua política é inequivocamente negativa” (Ehrhardt, 1998, p. 305, nossa tradução).

É possível elencar numerosas passagens em que se demonstra o desprezo de Tácito pelos bárbaros orientais. Os armênios "ignoravam a liberdade" e, portanto, toleravam a "escravidão" sob os partos (13.34); os habitantes de Tigranocerta, na Armênia, são, por natureza, covardes e traiçoeiros (14.23); Vologeses I pretende-se moderado apenas após satisfazer sua soberba (15.15); os partos não só aceitam, como também recompensam, a nefasta instituição dos eunucos (6.31); oreis partos, como Artabano, são arrogantes contra Roma, além de cruéis e inclementes com seus próprios súditos $(6: 31 ; 36)$.

Além desta óbvia constatação, contudo, há muito a ser explorado. Em especial, é preciso notar que o império oriental fornece matéria com a qual Tácito ironiza a degradação da política romana, sobretudo por meio de ressonâncias e estratégias alusivas. Assim, o juízo de Tácito sobre os orientais e, em particular, 
os arsácidas, deve ser temperado pela sua dura crítica aos próprios romanos, aviltados pela decadência moral de seus governantes.

A primeira aparição dos partos nos Anais de Tácito ocorre em 2.2, onde o autor descreve a chegada de uma delegação parta a Roma requisitando o retorno do príncipe Vonones, filho de Fraates IV, a fim de estabelecê-lo como rei. As menções ao massacre de Fraates e seus sucessores em disputas familiares, à desordem causada pela adoção de um rei criado à moda estrangeira e ao desgoverno da Armênia (2.2-4) não constituem expediente gratuito. Inseridas no início do segundo livro dos Anais, começam onde termina um lúgubre vaticínio sobre a sorte da República sob a condução de Tibério e seus sucessores (1.81). O massacre dos bárbaros pospõe-se aos artifícios de Tibério e sua mãe contra o próprio Augusto (1.5) e seu neto, Agripa Póstumo (1.6). Prefigura, ademais, a sina de Germânico (2.5; 2.43) e Agripina Maior (6.25). A acusação contra a indolência e as maneiras estrangeiras de Vonones mais parece uma denúncia contra os próprios Césares, em especial o futuro Nero e seus arroubos filo-helênicos (15.33). E o desgoverno da Armênia, inclusive com direito à ginecocracia (2.4), reverbera a crítica à domesticação do Império nas mãos de mulheres como Lívia e Agripina Menor (L’Hoir, 1994).

Do ponto de vista estrutural, a digressão parta no início do segundo livro tem um significado particular. Segundo a narrativa de Flávio Josefo, Musa teria tramado para assegurar a sucessão tranquila de Fraates V, com o exílio dos demais herdeiros e o envenenamento do rei Fraates IV, evento que deveria ter sido conhecido, em algum grau, em Roma (Josefo $A J$ 18.39-43). A narrativa é notavelmente similar à versão da morte de Augusto por Lívia e a ascensão de Tibério em Tácito (1.5). De forma geral, a ideia de um poder usurpado pelo elemento feminino, com a recorrente narrativa de mulheres que "fazem" imperadores (Rutland, 1978), certamente aludiria à percebida degeneração política do Oriente, onde, para uma longa tradição romana, o governo feminino era bem aceito (QuintoCúrcio 10.1.37-38; cf. Lerouge, 2007, p. 262). Embora a morte de Fraates IV preceda em mais de uma década a morte de Augusto, Tácito prefere retardar o relato desse episódio e, por meio de alusões genéricas, atrela o início dos dois primeiros livros à sangrenta sucessão de duas casas imperiais.

Ao longo do segundo livro, notícias da fronteira oriental intermeiam a carreira de Germânico até que ambas as frentes, por assim dizer, se encontram. 
De início, Tibério utiliza a comoção no Oriente para afastar Germânico, pois considerava-o uma ameaça. Mais de uma vez, Tácito sugere que a conspiração de Cneu Calpúrnio Pisão contra Germânico, resultando em seu suposto envenenamento, teria sido promovida por Tibério ( $2.43 ; 3.15-16)$. Na narrativa sobre a questão armênia, Tácito sujeita a descrição dos partos a um interesse maior, o enaltecimento de Germânico. Assim, as ações no Oriente, como a coroação, na Armênia, de um rei aliado $(2.56$; 2.64) e um acordo celebrado com Artabano (2.58) são apresentadas de forma favorável ao herói. A carreira de Germânico é expressamente comparada à biografia de Alexandre: um jovem e competente general, morto em terras estrangeiras por seus iguais (2.73). Nesse sentido, sua recepção favorável pelos partos (2.58) e egípcios (2.59), bem como outros povos, deve ter tido a finalidade de aproximar sua figura daquela do conquistador macedônio. Vislumbra-se, na campanha parta, uma associação à campanha contra os antigos persas.

O livro sexto traz a história de uma conspiração da aristocracia parta contra Artabano III (cf. nossa introdução histórica). Mais uma vez, Tácito combina a narrativa da política doméstica à política externa, realçando as similaridades entre Roma e Pártia. O banho de sangue promovido por Artabano contra seus próprios parentes (6.31) em nada surpreenderia uma audiência à qual se acabara de relatar as mortes de Druso César e Agripina Maior (6.24-25), injustamente punidos nas perseguições conduzidas por Sejano e Tibério. Um déspota adulado pelo Senado e odiado pelo povo $(6.23$; 30), Tibério não era menos tirânico que Artabano, este também, outrora, um aliado do Senado de Selêucia contra o povo (6.42). E o rei Tirídates III, imposto pelos romanos, é denunciado como um fantoche de seu conselheiro Abdageses (6.43), assim como Tibério é um fantoche, ora de Sejano, ora de Macro (6.45).

O mesmo jogo de alusões perdura nas narrativas seguintes. O discurso de Cláudio sobre o despotismo dos partos (12.11), às vezes considerado uma expressão do próprio pensamento taciteano, representa mais bem uma crítica ao seu reinado. A passagem é cheia de ironias, e ninguém poderia esperar um governante menos qualificado do que este imperador para pregar aos outros as virtudes da clemência e da moderação. Nas palavras de Elizabeth Keitel (1978, p. 466467), 
A pomposa palestra de Cláudio aos partos em 12.11 sobre os princípios do bom governo é repleta de ironias em relação ao seu próprio governo. A alardeada clementia do princeps frequentemente implica a punição de inocentes (...) ou o perdão dos culpados (...). A sua administração da justiça é errática e subjetiva (...) (nossa tradução).

A mesma Elizabeth Keitel (1978, p. 462-465), examinando a presença da Pártia e da Armênia nos "livros de Cláudio" (11 e 12), demonstra seu estreito vínculo com o tema do despotismo e da degradação da política dinástica romana. A disputa entre os irmãos Gotarzes e Vardanes (11.8-10) prefigura a rivalidade de Nero e Britânico (11.11), o domínio violento de Vardanes e Gotarzes (11.10; 11.10) é descrito em termos similares ao caráter de Agripina Menor (12.7; 12.22; 13.13; $13.2 ; 13.21)$ e as tramas contra os soberanos Vardanes e Cláudio são aproximadas por uma mesma linguagem (11.8 e 11.26; cf. Ehrhardt, 1998, p. 297).

No livro 15, Tácito reconta os motivos que levaram romanos e partos a uma nova disputa pela Armênia. Apesar das não raras críticas ao temperamento de Vologeses I, Tácito parece sugerir que até mesmo um bárbaro era capaz de maior moderação que Nero. O discurso de Vologeses I contra as disputas fratricidas (15.1-2) e seu afeto por Tirídates, o irmão, contrastam fortemente com as ações de Nero contra Britânico (13.16). Até mesmo a resolução bélica de Tirídates (15.1) e o relativo valor militar de Vologeses (15.11-13), ainda que inferiores à liderança de Córbulo, superariam as "qualidades” de Nero, um imperador mais propenso a cantarolar e escrever poesia (14.16; 15.39).

A essa altura, seria útil recordar o caso da representação taciteana de Boudica, que, sendo pertinente à avaliação dos bárbaros em Tácito, apresenta obstáculos similares de interpretação. Esposa do falecido rei Prasutagus, a rainha dos icenos, Boudica, se queixa dos abusos cometidos pelos romanos, em especial o estupro de suas filhas. Ela lidera uma malfadada revolta contra a Roma neroniana (14.35-37).

Os especialistas têm opiniões divergentes sobre a avaliação de Boudica em Tácito. Para Santoro L’Hoir (1994, p. 9), a rainha bárbara integra uma galeria de mulheres usurpadoras do poder masculino, ao lado de Agripina Menor e Lívia, todas responsáveis por desgraçar e escravizar suas respectivas nações. Kaitlyn Pettigrew (2013, p. 98-103) acredita que a apresentação de Boudica como uma mãe protetora das filhas violadas se enquadraria na concepção romana idealizada 
de uma matrona, atraindo a simpatia das audiências. Eric Adler (2008, p. 181, 184), por sua vez, argumenta que o discurso final em favor da "liberdade" seria uma incômoda contraposição ao estado de coisas que vigorava no período neroniano. Michael Roberts (1988, p. 128-129) defende que a atribuição do discurso de liberdade à rainha derrotada expressa um vínculo entre a imaginada irracionalidade feminina e a total impossibilidade de resistir ao imperialismo romano.

Estas divergências se alimentam de uma ambiguidade ínsita ao relato de Tácito. A inserção das descrições dos estrangeiros em contexto dificulta a teorização de avaliações unívocas. No caso de Boudica, por exemplo, Adler (2008, p. 194) advoga persuasivamente pelo caráter híbrido da sua representação em Tácito. As referências às transgressões dos papéis de gênero, à covardia romana e à liberdade provocariam, em cada caso, estranhamento, reprovação e simpatia.

Da mesma forma, o tratamento dispensado por Tácito aos partos tem alguma ambiguidade. Evidentemente, preconceitos genéricos contra os bárbaros não poderiam faltar ao relato, mas a comparação da Pártia aos descaminhos de Roma enfraquece, em algum grau, as fronteiras entre os dois mundos. Déspotas como Tibério não são muito melhores que seus pares na Pártia. Pelo menos uma vez, um discurso inequivocamente romano é colocado na boca de um parto (2.2), o que deveria suscitar alguma simpatia nas audiências dos Anais. Além disso, diversos paralelos conferem uma coloração favorável aos líderes orientais. ${ }^{12}$ Os reis "alienados" e enviados pelos romanos à Pártia são geralmente covardes, fracos e, portanto, rapidamente derrotados, o que depõe mais contra a "formação" imperial do que o contrário. Assim, o retrato que o autor faz dos partos não é de todo plano.

\section{Guerra dos Mundos}

Charlotte Lerouge e Holger Sonnabend convergem em sua avaliação dos Anais ao indicar a persistência, mesmo em Tácito, da temática augustana do "mundo dividido" em dois (Lerouge, 2007, p. 144-146; Sonnabend, 1986, p. 219).

\footnotetext{
${ }^{12}$ Mencionamos, acima, o caso de Vologeses I e Tirídates em face de Nero e Britânico. Keitel (1978, p. 471-472) também cita o relato sobre o amor conjugal de Zenóbia e Radamisto da Armênia (12.51), em intenso contraste com a relação de Cláudio e Agripina Menor (Tac. Ann. 12.68).
} 
Segundo a teoria instaurada por Sonnabend (1986, p. 202-203), por vezes apelidada de Zwei-Welten Theorie, Augusto, após a devolução das insígnias romanas, teria buscado uma política de coexistência mais ou menos pacífica com os partos, atrelando a essa abordagem diplomática um novo discurso sobre os arsácidas. Parte dessa nova retórica envolvia reconhecer no inimigo uma potência equivalente, com a qual se deveria partilhar a orbe -, postura que, ademais, tem algum reflexo na iconografia da época (Rose, 2005, p. 23, 33-35). Essa influente hipótese é reverberada em autores como Maria Brosius (2006, p. 136), Rahin Shayegan (2011, p. 335) e Wiebke Vergin (2013, p. 90).

O vigor e popularidade da propaganda augustana são irrecusáveis nas obras de Estrabão (Geog. 11.9.2), Veleio Patérculo (2.101.2) e Pompeu Trogo (Just. Epit. 41.1.1). Sua persistência em um autor tardio como Tácito, contudo, se presta a alguns questionamentos. ${ }^{13}$ Num período em que o tema da conquista supostamente se impõe, passando a nortear as ações romanas na Armênia e na Mesopotâmia, é de se perguntar por que motivos teria o historiógrafo tão insistentemente se adstrito a uma visão historicamente superada.

Parcialmente, esse tratamento talvez se imponha por avaliações pessoais de estratégia militar ou por mera fiabilidade histórica. De outro lado, a leitura cuidadosa das passagens geralmente mobilizadas em apoio da hipótese do mundo dividido poderia mitigar o impacto e alcance que teriam nas prováveis audiências. E, é claro, é possível que o próprio apelo da conquista não fosse ainda tão pronunciado como se pensou. Um exame de algumas passagens, portanto, pode ser elucidativo.

Em 2.2, como já mencionado, Tácito descreve a chegada de uma delegação parta a Roma que, devido à extinção da linha sucessória de Fraates, solicita ao imperador autorização para instalar no trono Vonones, um destes príncipes que os romanos mantinham na capital como garantia de seus tratados com os arsácidas. Pouco depois, diz-se, a nobreza parta se queixa do novo rei, sacado a um outro mundo (alio ex orbe rex) e degenerado por uma criação débil. Essa pas-

${ }^{13}$ Sonnabend (1986, p. 219) prevê a "possível objeção de que Tácito teria introduzido ideias de sua própria época", mas a considera frágil, afirmando que "sua argumentação se orienta estreitamente pelas ideias que já são visíveis na época de Augusto” (nossa tradução). 
sagem, que, como é habitual na historiografia latina, coloca na boca de um bárbaro um discurso idealizado e tipicamente romano, é invocada como um dos exemplos da teoria dos dois mundos.

Se é verdade, de um lado, que a expressão alius orbis aponta para o imaginado abismo entre partos e romanos, de outro, ela não demonstra a alegada equivalência entre eles. Apesar de sua consciência da importância e do poder dos partos, do que é testemunho sua terminologia, Tácito poderia estar apenas reconhecendo, a contragosto, a importância de um inimigo (Ehrhardt, 1998, p. 305; cf. 2.57).

Uma análise sistemática da narrativa de Tácito, contudo, não deixa dúvidas quanto à recorrência do tema, com implicações qualitativas. Em outro trecho bastante significativo, que diz respeito à passagem de Germânico pelo Egito (2.60), a grandeza do "império" de Ramsés, aferida pela (fictícia) lista de províncias tributárias em uma proclamação real, é comparada ao poder de partos e romanos. A descrição da Armênia como um país enclausurado por dois "vastos impérios”, Roma e Pártia, também se harmoniza com essa concepção (2.56). Não nos esqueçamos, por fim, do discurso de Tirídates, irmão de Vologeses I, que insere a Pártia no rol dos magna imperia (15.1).

Não parece correto Ehrhardt (1998, p. 305), portanto, ao questionar a pertinência da questão da divisio orbis em Tácito. Esse autor não apenas deixa de comentar passagens em que a ideia aparece de forma clara, como também invoca como argumento uma perspectiva da política externa romana que se aplicaria, sem problemas, a outros autores do período augustano, onde a temática parece indiscutível. Como explicar, portanto, a persistência desse tema nesse momento?

A ideia dos dois mundos, como foi dito, teria se atrelado a uma política externa defensiva e à aceitação da impossibilidade de se conquistar os inimigos partos (Spawforth, 1994, p. 240-241). Essa ideologia foi fortemente associada à tradição da resistência grega aos persas e, assim, os partos foram quase automaticamente vinculados pelas elites romanas à Pérsia Aquemênida (Spawforth, 1994, p. 242-243). Uma série de eventos, contudo, confirmam a importância do tema da guerra defensiva dos gregos contra os persas até pelo menos o século III d.C., não se limitando à Era de Augusto. Essa iconografia, sem dúvida, continuava 
aludindo à expulsão dos invasores (Spawforth, 1994, p. 238-239) e não forçosamente à conquista. ${ }^{14}$

Além disso, como esclarece Charlotte Lerouge (2007, p. 119-120), a própria teoria de Sonnabend não se sustenta totalmente quando se pensa no período augustano. Os temas da conquista e da resistência não chegam a ser excludentes e as fontes sugerem algum grau de convivência entre eles. Essa constatação, contudo, cria dificuldades consideráveis em se explicar a ideia dos dois mundos. Lerouge (Lerouge, 2007, p. 122) propõe que o modelo se prestasse a escamotear os problemas na fronteira ocidental, transmitindo a falsa noção de estabilidade, mas essa teoria não é particularmente convincente, sobretudo como argumento para sua persistência muitas décadas depois.

Tampouco parece haver uma explicação estratégica para a veiculação desse tema em Tácito. A política defensiva de Augusto não é tida como sinal de moderação, mas como resultado de "medo ou inveja" (1.11). A derrota de Cesênio Peto contra os partos, sua incapacidade de preservar aquilo que havia tomado, não poderia ser tomada como alerta ou crítica à campanha de Trajano, à semelhança do juízo de Dio Cássio (68.33), já que o fracasso é nitidamente atribuído às decisões de um só homem, sendo revertido, mais tarde, por Córbulo (Pomeroy, 2017, p. 12). Na verdade, o destaque da Pártia numa obra como os Anais parece refletir, em alguma medida, o crescente interesse de Roma pela conquista desse império inimigo.

Em Tácito, em particular, é possível que a ideia se relacionasse à noção de translatio imperii (2.70). Graças à tradição grega sobre a Pérsia, a Pártia passou a fazer parte de uma história de sucessão imperial à qual os próprios romanos se vinculavam. Os partos, como os romanos, eram percebidos como sucessores dos aquemênidas e macedônios, detentores de domínios "universais". Nenhuma outra nação estava em situação similar. Nesse sentido, a ideia deve ter tido uma vitalidade única. Infelizmente, um exame exaustivo da origem da ideia de divisio orbis, tomando-se em conta a vasta documentação do período romano, não pode ser empreendida aqui.

${ }_{14}$ Também Josefo, num período não tão recuado, expressa a ideia do mundo dividido ( $A J$ 18.46). 


\section{Uma Verdade Possível}

Como Tácito pode contribuir para nosso conhecimento da história do Irã? Quais eram as fontes de Tácito? É correto aquilo que o autor afirma sobre os partos? Essas são questões frequentes a emanar das discussões sobre a credibilidade dos Anais. Tópicos importantes envolvem descrições da relação entre rei e nobreza, a constituição política das cidades e a ideologia real.

Já foram apontados motivos que permitem colocar a credibilidade do autor em xeque. ${ }^{15}$ Ao instrumentalizar suas digressões párticas em função de escopos narrativos maiores, Tácito certamente distorceu alguns episódios da história política oriental. Comparações entre seus relatos e os de Josefo mostram, por vezes, discrepâncias, ${ }^{16}$ e os especialistas questionam informações dos Anais que não parecem plausíveis. ${ }^{17}$ De outro lado, ao relatar as tensões constantes entre nobreza e monarquia, o historiador parece fornecer informações confiáveis sobre o arranjo institucional arsácida (Ehrhardt, 1998, p. 298). Da mesma forma, sua descrição de Selêucia, com ênfase no elemento grego e na relativa independência formal, ${ }^{18}$ tem respaldo em outras fontes (Ehrhardt, 1998, p. 300).

Muitos autores tentaram, insistentemente, encontrar a verdade por trás do suposto discurso de Artabano III nos Anais, no qual o monarca reivindica as fronteiras do reino de Alexandre e dos aquemênidas (6.31), demonstrando uma consciência histórica e uma filiação ideológica que outras fontes não permitem aferir com facilidade. Se verdadeira, como pensam muitos autores (Ehrhardt, 1998, p. 299), a fala revelaria importantes modelos de conduta real dos arsácidas. Shayegan (2011, p. 302-307) propõe que, durante o domínio das dinastias arsácida e sassânida, vigoraram duas tradições contrastantes sobre Alexandre, uma sacerdotal e crítica e outra, positiva, preservada oralmente e refletida, mais tarde, no Shahnameh, o que confirmaria o relato de Tácito. O autor acredita, ainda, que os arsácidas foram estimulados pelo embate com Roma e por civilizações vizinhas

\footnotetext{
15 Para os romanos em geral, cf. Schneider, 2007, p. 60: “(...) pouca informação confiável sobre a Pártia estava disponível em Roma”.

16 Por exemplo, quanto à causa da morte de Gotarzes II: uma doença (Tac. Ann. 12.14) ou uma conspiração (Joseph. $A J$ 20.74)? Cf. Bivar, 1983, p. 79.

${ }_{17}$ A fuga de Vardanes pelas planícies da Báctria, por exemplo, parece improvável, já que a Hircânia estava sob controle do adversário (Bivar, 1983, p. 75).

${ }^{18}$ Sobre o senado de Selêucia, comparar com Plut. Crass. 32.3.
} 
(mas não por uma tradição inerentemente iraniana) a assumir um passado "aquemênida" (Shayegan, 2011, p. 330-331).

Como as fontes de Tácito não aparentam ter origem oriental, contudo, grande parte de suas afirmações devem depender de relatos autobiográficos e documentos oficiais (Ehrhardt, 1998, p. 297). O caráter superficial do conhecimento romano sobre a Pártia se reflete na carência das informações que temos sobre os arsácidas. Como assevera Bivar (1983, p. 80),

É uma característica da tradição histórica remanescente sobre a Pártia, derivada, como é, sobretudo de fontes romanas, que ela forma um interminável catálogo de expedições militares e demonstra pouco interesse pelos modos e aspirações partos. Os poucos partos mencionados na narrativa são retratados como figuras obscuras e as impressões informativas são raras, quando não totalmente ausentes (nossa tradução).

Essa verdade, é claro, não deve constituir censura à "qualidade" da historiografia clássica. Sem dúvida, não se pode esperar dos autores antigos os mesmos parâmetros de objetividade instaurados pela historiografia "científica". Por mais preocupados que fossem em relação à verdade, esses autores obedeciam a outras convenções textuais e é até mesmo questionável se teriam desejado um texto orientado pelo crivo moderno.

\section{Conclusão}

A escrita da história do Irã Antigo é repleta de dificuldades relativas à natureza das fontes disponíveis. Reconstruir sua trajetória política envolve, inevitavelmente, o exame minucioso de fontes estrangeiras e hostis, gregas ou latinas. Mais do que uma compilação de referências, a narrativa histórica dos arsácidas depende de uma interpretação das fontes que leve em conta seu contexto histórico e textual.

Tácito é uma das mais importantes fontes antigas sobre a história da Pártia e das relações romano-partas. Para entender sua avaliação dos arsácidas, bem como a relevância dos dados que ele nos traz, é preciso reinserir as narrativas de política externa no contexto geral dos Anais. Em mais de uma passagem, como tentou-se aqui demonstrar, os partos e os armênios são instrumentalizados pelo 
autor a fim de ressaltar os descaminhos dos próprios romanos. Seja como referência da espécie de tirania "oriental” em que Roma se transformara, seja como contraponto a ela, os arsácidas servem a um propósito narrativo que muitas vezes obscurece seu verdadeiro papel histórico.

Existem informações valiosas nos Anais, mas a cautela é indispensável. É crível, por exemplo, que Artabano se pensasse um sucessor dos aquemênidas e de Alexandre, mas outros discursos proferidos pelos partos nos Anais são bastante duvidosos. Em cada discurso, um exame sistemático da narrativa é de grande ajuda para elucidar seu valor histórico.

No geral, Tácito partilha os preconceitos de seus contemporâneos sobre a Pártia, reproduzindo clichês atávicos e veiculando a velha ideia da divisio orbis. Apesar disso, é improvável que Tácito concordasse com a política que inspirou a noção dos dois mundos, e sua postura em relação à Pártia decerto não pertence ao universo augustano. É mais provável, na verdade, que a importância ocupada pela Pártia em seus Anais refletisse uma preocupação presente, suscitada pelas campanhas de Trajano. Daí a importância de se reavaliar a evidência disponível com particular atenção aos anacronismos.

Artigo recebido em 11.12.2017, aprovado em 16.01.2018. 


\section{REFERÊNCIAS BIBLIOGRÁFICAS}

Fontes Primárias

Flávio Josefo. Flavii Iosephi opera. Tradução de B. Niese. Berlim: Weidmann, 1892.

Plutarco. Lives. Tradução de Bernadotte Perrin. Londres: William Heineman Ltd; Nova Iorque: G. P. Putnam's Sons. 1932.

Quinto-Cúrcio. Historia de Alejandro Magno. Tradução de Giovanni Porta. Milão: BUR, 2005.

Tácito. Annals (livros i-iii). Tradução de John Jackson. Londres, Cambridge (Massachusetts): Harvard University Press, 1992.

. Annals (livros iv-xii). Tradução de John Jackson. Londres, Cambridge (Massachusetts): Harvard University Press, 1986.

Annals (livros xiii-xvi). Tradução de John Jackson. Londres, Cambridge (Massachusetts): Harvard University Press, 1991.

\section{Bibliografia Crítica}

Adler, Eric. Boudica's speeches in Tacitus and Dio, Classical World, vol. 101, n. 2, 2008, p. 173-195.

Bivar, A. D. H. A political history of Iran under the Arsacids. In: Yarshater, Ehsan (ed.). The Cambridge History of Iran (vol. 3, part 1): the Seleucid, Parthian and Sasanian Periods. Cambridge, Londres, Nova Iorque, New Rochelle, Melbourne, Sydney: Cambridge University Press, 1983.

Bbrosius, Maria. The Persians. Nova Iorque: Routledge, 2006.

Debevoise, Neilson C. A political history of Parthia. Chicado, Illinois: University of Chicago Press, 1938.

Ehrhardt, Norbert. Parther und parthische Geschichte bei Tacitus. In: Wisehöfer, Josef (ed.). Das Partherreich unf seine Zeugnisse/ The Arsacid Empire: sources and documentation. Beiträge des internationalen Colloquiums, Eutin. Suttgart: Franz Steiner Verlag, 1998.

Keitel, Elizabeth. The role of Parthia and Armenia in Tacitus Annals 11 and 12, American Journal of Philology, vol. 99, n. 4, 1978, p. 462-473.

Koebner, Richard. Despot and despotism: vicissitudes of a political term, Journal of the Warburg and Courtauld Institutes, vol. 14, n. 3/4, 1951, p. 275-302.

Lerouge, Charlotte. L'image des Parthes dans le monde gréco-romain: du début du Ier siècle av. J.-C. jusqu'à la fin du Haut-Empire romain. Stuttgart: Franz Steiner Verlag, 2007.

L'Hoir, Francesca Santoro. Tacitus and women's usurpation of power. The Classical World, vol. 88, n. 1, 1994, p. 5-25. 
Milnor, Kristina. Women in Roman historiography. In: Feldherr, Andrew (ed.). The Cambridge Companion to the Roman Historians. Cambridge: Cambrdige University Press, 2009.

Nogueira, Érico. A Lírica Laudatória no Livro Quarto das Odes de Horácio. Dissertação de Mestrado, letras clássicas, departamento de letras clássicas e vernáculas, Universidade de São Paulo, 2006.

Oakley, Stephen P. Res olim dissociabiles: emperors, senators and liberty. In: Woodman, A. J. (ed.) The Cambridge Companion to Tacitus. Cambridge: Cambridge University Press, 2010.

Pettigrew, Kaitlyn. Foreign women in latin literature: the representation of Boudicca. Tese, Departamento de Estudos Clássicos, University of Western Ontario, 2013 .

Pomeroy, Arthur J. Fabius and Minucius in Tacitus: intertextuality and allusion in Annals book 15, The Classical Quarterly, 2017, p. 1-14.

Roberts, Michael. The revolt of Boudicca and the assertion of libertas in Neronian Rome, The American Journal of Philology, vol. 109, n. 1, 1988, p. 118-132.

Rose, Charles Brian. The Parthians in Augustan Rome, American Journal of Archaeology, vol. 109, 2005, p. 21-75.

Rutland, Linda W. Women as makers of kings in Tacitus' Annals, The Classical World, vol. 72, n. 1, 1978, p. 15-29.

Schmitt, Rüdiger. The Bisitun Inscriptions of Darius the Great: Old Persian Text. Londres: Corpus Inscriptionum Iranicarum, 1991.

Schneider, Rolf Michael. Bunte Barbaren: Orientalenstatuen aus farbigen Marmor in der römischen Repräsentationskunst. Worms: Wernersche Verlagsgesellschaft, 1986.

. Friend and Foe. The Orient in Rome. In: Curtis, Vesta Sarkhosh (eds.): The Age of the Parthians. Londres: I. B. Tauris, 2007.

Sayegan, M. Rahim. Arsacids and Sasanians: political ideology in Post-Hellenistic and Late Antique Persia. Cambridge: Cambridge University Press, 2011.

Simpson, Christopher J. Where is the Parthian? The Prima Porta Statue of Augustus Revisited, Latomus, vol. 64, fasc. 1, 2005, p. 82-90.

Sonnabend, Holger. Fremdenbild und Politik: Vorstellungen der Römer von Ägypten unde dem Partherreich in der späten Republik und frühen Kaiserzeit. Berna, Frankfurt am Main, Nova Iorque: Peter Lang, 1986.

Spawforth, Antony. Symbol of unity? The Persian-Wars tradition in the Roman Empire. In: Hornblower, Simon (ed.). Greek historiography. Oxford: Clarendon Press, 1994.

Syme, Ronald. Tacitus (vols. 1-2). Oxford: Clarendon Press, 1958. 
Timpe, Dieter. Die Bedeutung der Schlacht von Carrhae, Museum Helveticum, vol. 19, n. 2, 1962, p. 104-129.

Vergin, Wiebke. Das Imperium Romanum und seine Gegenwelten: die geographisch-ethnographischen Exkurse in den "Res Gestae" des Ammianus Marcellinus. Berlin; Boston: De Gruyter, 2013.

Walser, Gerold. Rom, das Reich und die fremden Völker in der Geschichtsschreibung der frühen Kaiserzeit: studien zur Glaubwürdigkeit des Tacitus. Basileia: Helbing \& Lichtenhahn, 1951.

Wiesehöfer, Josef. Ancient Persia: from 550 BC to 650 AD. Traduzido por Azizeh Azodi. Londres, Nova Iorque: I. B. Tauris, 2001.

La Persia antica. Tradução de Alessandro Cristofori. Bolonha: Il Mulino, 2003.

Wissemann, Michael. Die Parther in der augusteischen Dichtung. Frankfurt am Main, Berna: Peter Lang, 1982. 